\title{
Impact of Educational Program on Nurses' Knowledge toward Coronary Artery Bypass Graft Surgery in Mosul Teaching Hospitals
}

\author{
Tahsein Muhsin Hussein ${ }^{1}$, Myasar Mohsin Azeez ${ }^{2}$, Radhwan Hussein Ibrahim ${ }^{3}$ \\ ${ }^{1}$ Lecturer, Adult Nursing, College of Nursing, University of Mosul, ${ }^{2}$ Assistant Lecturer, Nursing Department, \\ Technical Institute, Mosul, ${ }^{3}$ Professor, Community Health Nursing, College of Nursing, University of Mosul
}

\begin{abstract}
Background: Coronary artery bypass grafting $(\mathrm{CABG})$ is a common surgery to treat coronary artery disease which is the leading reason of death in advanced countries. It involves a section of a vein or an artery to produce a connection (or bypass) between the aorta and the coronary artery beyond the obstruction.
\end{abstract}

Objectives: The objectives of the study were to assess the nurses' knowledge toward CABG, to identify the impact of the educational program, and to determine the relation between nurses' knowledge and their demographical characteristic.

Method: A quasi-experimental study was conducted to assess the effectiveness of educational program on nurses' knowledge regarding to CABG. A non-probability purposive sample consisting of (40) nurses. The samples were divided into two equal groups (study and control). An educational program was focus to administer for the study group. All participants completed a self-administered instruments at pre and post-tests. The assessment was carried out during the period from $17^{\text {th }}$ of January, 2018 to $4^{\text {th }}$ of May, 2018. The Instrument validity was determined through content validity, by a panel of experts.Reliability of the instrument was determined through the use of test- retest approach.

Results: The results revealed that the mean post- test knowledge scores in the study group were significantly higher than mean pre- test knowledge score.

Conclusion: The study concluded that the educational program had great effective on emerging and enhancing nurses> knowledge regarding $\mathrm{CABG}$.

Keywords: Coronary artery bypass graft, educational program, nurses knowledge.

\section{Introduction}

Cardiovascular disease is the prominent cause of death worldwide, accounting for $31 \%$ of all recorded deaths, and is expected to continue in this point until $2030^{(1,2)}$. The most common of these is the coronary artery disease which represents the leading cause of

\footnotetext{
Corresponding Author:

Radhwan Hussein Ibrahim

Professor, Community Health Nursing, College of

Nursing, University of Mosul

e-mail: prof.dr.radhwan@uomosul.edu.iq
}

death in developed countries ${ }^{(3,4,5)}$. Today, coronary artery bypass surgery (CABG) remains one of the most generally done main surgical treatment worldwide and the most common procedure performed by cardiac surgeons ${ }^{(6,7,8)}$. This surgery has supported to be one of the most effective and lasting therapies for ischemic heart disease ${ }^{(9,10)}$. Coronary artery bypass surgery is a surgical method which may be uses arteries or veins as a graft to convey blood to an area of the coronary artery distal to the blockage ${ }^{(11,12)}$. A coronary artery bypass surgery (marked" cabbage") ${ }^{(13)}$. Coronary artery bypass graft surgery has a positive effect on mortality in several cases ${ }^{(14)}$. American Heart association position statement specified that $\mathrm{CABG}$ is indicated if medical 
management does not satisfactorily control angina in patients with coronary artery disease or if the patient has $>50 \%$ obstruction of the left maincoronary artery or three vessel disease with moderate or severe left ventricular dysfunction regardless of symptoms ${ }^{(15)}$. Extra of 400,000 American (greatest of them male) undergo $\mathrm{CABG}$ every year, making it one of the most common cardiac surgeries. Successful CABG can relieve angina chest pain, progress cardiac function, progress the patient's quality of life, also they experience more active, exercise performance increases and support them to return to the normal lives, but the early recovery period presents a numeral of challenges for patients care and nurses ${ }^{(16,17,18)}$. In the US and an average incidence rate of (62) per 100,000 inhabitants in western European countries $^{(19,20)}$.Early and adequate discharge planning based on in-depth knowledge of the post discharge experience will help to ensure optimal recovery ${ }^{(21)}$.

\section{Method and Subjects}

Quantitative research, a quasi- experimental study was carried out to assess nurses' knowledge in AlJamhuree and al- Salam Teaching Hospitals in Mosul City from $17^{\text {th }}$ of January, 2018 to $4^{\text {th }}$ of April, 2018. It was carried throughout the application of pre and post-tests approach for the study group and control groups. A non - probability purposive sample of (40) nurses (male and female) who were working in cardiac care wards, who met the sample criteria were included in the study, which was divided into two groups; the first group consists of (20) nurses for study group were exposed to the health educational program, while the second group (20) nurses for control group. Each group had proximately the same demographic characteristics as possible. To fulfill the objectives of the study aclosedended questions structured knowledge questionnaire was preparedbased on a comprehensive review of relevant literatures to evaluate the nurses knowledge before and after the administration of educational program. It consists of two parts:-Part One: Related to the nurses demographical characteristics sheet which include (age, gender, level of education, years of experience in cardiac wards, and number of attending educational programs regarding CABG).Part Two: Questionnaire to Assess Nurses〉 Knowledge Regarding CABG,this part involves of (20) items. All items were measured by nominal scale of normal which was given a score of two for the correct answer and one for the wrong answer. The knowledge mean of scores was rated into (3)knowledge levels, according to the two-point likert scale $=$ (Maximum Minimum $) /$ groups $=(2-1) / 3=(0.33)$ this is the interval value which was the added value to the three levels as in the following:1- 1.339 (Poor), 1.34-1.669(Moderate), and $1.67-2$ (High). The tools validity was done by a panel of experts in different specializations, Reliability was tested by test-retest the correlation coefficient was $(\mathrm{r}=0.88 \%)$ at the level $(\mathrm{p} \leq 0.05)$ for nurses' knowledge. This indicated that the instrument was adequately reliable.All the results were analyzed using the statistical package SPSS 18.0. A statistical and inferential analysis was applied for data analysisconcentration on the calculation of the frequency, percentage, paired t-test, Pearson coefficient correlation, mean of score (MS), and one- way analysis of variance.A $p$ value $\leq 0.05$ was regarded statistically significant.

\section{Results}

Table 1: Comparative differences between the study and control groups of the nurses' knowledge relative to pre and post- tests.

\begin{tabular}{|c|c|c|c|c|c|}
\hline Knowledge & Mean of Score & Std. Deviation & Std. Error Mean & t- Observe & Sig. \\
\hline Pair 1 pre-test for study G. & 1.3225 & .06382 & .01427 & \multirow{2}{*}{0.665} & \multirow{2}{*}{$\begin{array}{l}.514 \\
\text { N.S }\end{array}$} \\
\hline Pre-test for control G. & 1.3100 & .05758 & .01288 & & \\
\hline Pair 2 pre-test for study G. & 1.3225 & .06382 & .01427 & \multirow{2}{*}{-17.979} & \multirow{2}{*}{$\begin{array}{c}.000 \\
\mathrm{~S} .\end{array}$} \\
\hline Post-test for study G. & 1.8100 & .08974 & .02007 & & \\
\hline Pair3 pre-test for control G. & 1.3100 & .05758 & .01288 & \multirow{2}{*}{0.370} & \multirow{2}{*}{$\begin{array}{l}.716 \\
\text { N.S }\end{array}$} \\
\hline Post-test for control G. & 1.3050 & .03940 & .00881 & & \\
\hline Pair4 Post-test for study G. & 1.8100 & .08974 & .02007 & \multirow{2}{*}{21.508} & \multirow{2}{*}{$\begin{array}{c}.000 \\
\text { S. }\end{array}$} \\
\hline Post-test for control G. & 1.3050 & .03940 & .00881 & & \\
\hline
\end{tabular}

$\mathrm{T}$ - critical $=2.093 \quad \mathrm{DF}=19$ 
Table 2: Association between nurse' knowledge scores with gender.

\begin{tabular}{|l|c|c|c|c|c|c|}
\hline Gender & No. & Mean of score & Std. Deviation & t - observe & t. critical & Sig. \\
\cline { 1 - 6 } Male & 15 & 1.8133 & 0.08958 & 0.281 & \multirow{2}{*}{0.781} & \\
\cline { 1 - 5 } Female & 5 & 1.8000 & 0.10000 & 0.265 & & 0.265 \\
\hline
\end{tabular}

Table 3: Analysis of variance of participants knowledge according to their demographical characteristics.

\begin{tabular}{|c|c|c|c|c|c|c|}
\hline Variable & Source of variance & Sum of Squares & DF & Mean Square & $\mathbf{F}$ & Sig. \\
\hline \multirow{3}{*}{ Age } & Between Groups & 1.550 & 4 & .388 & \multirow{3}{*}{.930} & \multirow{3}{*}{.473} \\
\hline & Within Groups & 6.250 & 15 & .417 & & \\
\hline & Total & 7.800 & 19 & & & \\
\hline \multirow{3}{*}{ Educational level } & Between Groups & 3.478 & 4 & .869 & \multirow{3}{*}{.950} & \multirow{3}{*}{.462} \\
\hline & Within Groups & 13.722 & 15 & .915 & & \\
\hline & Total & 17.200 & 19 & & & \\
\hline \multirow{3}{*}{$\begin{array}{l}\text { Years of } \\
\text { Experience }\end{array}$} & Between Groups & 3.028 & 4 & .757 & \multirow{3}{*}{1.901} & \multirow{3}{*}{.163} \\
\hline & Within Groups & 5.972 & 15 & .398 & & \\
\hline & Total & 9.000 & 19 & & & \\
\hline \multirow{3}{*}{$\begin{array}{l}\text { No. of attended } \\
\text { Educational } \\
\text { program }\end{array}$} & Between Groups & 2.050 & 4 & .513 & \multirow{3}{*}{1.139} & \multirow{3}{*}{.376} \\
\hline & Within Groups & 6.750 & 15 & .450 & & \\
\hline & Total & 8.800 & 19 & & & \\
\hline
\end{tabular}

F. Critical $=3.24 \mathrm{P} \leq 0.05$

Table (4): Comparison between nurses' knowledge scores regarding (pre and post) tests for the study and control groups.

\begin{tabular}{|c|c|c|c|c|c|c|c|c|c|c|c|c|}
\hline \multirow{3}{*}{ Knowledge levels } & \multicolumn{6}{|c|}{ Study group $n=20$} & \multicolumn{6}{|c|}{ Control group $n=20$} \\
\hline & \multicolumn{3}{|c|}{ Pre test } & \multicolumn{3}{|c|}{ Post test } & \multicolumn{3}{|c|}{ Pre test } & \multicolumn{3}{|c|}{ Post test } \\
\hline & No (\%) & M.S & G. & No (\%) & M.S & G. & No $(\%)$ & M.S & G. & No (\%) & M.S & G. \\
\hline Poor (1-1.339) & $15(75 \%)$ & \multirow{3}{*}{1.32} & \multirow{3}{*}{ L.S } & 0 & \multirow{3}{*}{1.81} & \multirow{3}{*}{ H.S } & $16(80 \%)$ & \multirow{3}{*}{1.31} & \multirow{3}{*}{ L.S } & $17(85 \%)$ & \multirow{3}{*}{1.30} & \multirow{3}{*}{ L.S } \\
\hline Moderate (1.34-1.669) & $5(25 \%)$ & & & $4(20 \%)$ & & & $4(20 \%)$ & & & $3(15 \%)$ & & \\
\hline High (1.67-2) & 0 & & & $16(80 \%)$ & & & 0 & & & 0 & & \\
\hline
\end{tabular}

M.S= Mean of score, $\mathrm{G}=$ Grads, L.S= Low significant, H.S= High significant.

\section{Discussion}

Throughout of the data analysis, In relation to the age, the results of the present study showed; that more than half of the nurses in both study and control groups belonged to the same age group of (30-39) years old. This finding is in concordance with that of ${ }^{(22)}$ who found that their age ranged between 20 and 40 years. The high percentage of male nurses in the present study. The researcher refer to this finding which is due to the dominance of male in the nursing profession in Iraq. On the other hand, this results may be imitate a social conditions keeping women away in this job and due to the fact that most of female nurses are selected to care for maternal and child health care. This finding is disagree with a study done by ${ }^{(23,24)}$, who definite that the majority of nurses were female. Moreover, the current study revealed that the institute nursing graduate were the high proportion, more than half of them their years of experience in cardiac wards less than (5) years and more than three quarters of them have no attendance in any education programs related to coronary artery bypass grafting. The above findings were consistent with another study done by ${ }^{(25)}$, shown that nursing school diploma was the high proportion. Also, more than half 
of them their experiences less than (10) years and the majority of them have no in service training course related to coronary artery bypass graft surgery. As well, Supporting to this findings ${ }^{(26)}$ stated that the majority of nurses in both units had secondary diploma degree and most of nurses in both units had not trained.

In order to assess the effect of educational program upon nurses' knowledge through scoring analysis for mean of score. The findings of the current study had presented that, the mean of the nurses' knowledge score was $(1.32,1.31)$ for both study and control groups respectively during pre-test, which was reflects the poor of their knowledge before the administration of the educational program. After program implementation for the study group subjects, the nurses' knowledge mean of score was (1.81) had shown highly significant improvement in post-test when they are compared with control group (1.30). The above results indicated that the educational program was very efficient in enhancing the knowledge level of the respondents. This finding goes in with the previous study done by ${ }^{(27,28)}$ whomentioned that nurses must be able to expand their knowledge of this area through ongoing education, Journal, and seminars. Consequently, teaching programs for nursing staff constitute an important part. These programs are urgently designed to assess nursing staff in developing and enhancing the skills needed to provide high standards of care to their patients.In this respect, ${ }^{(29)}$ reported that many continuing education program evaluations use a comparison of the participant's pretest and post test scores as an indicator of that program's effectiveness. The results of the recent study indicated that the selected demographic variable had shown no statistical significant association with the nurses knowledge scores. This findings agree with another study done by ${ }^{(30)}$ who revealed that the all demographic variables i.e. age, sex, educational qualification, experience in post-operative management of CABG and availability of any additional information on post- operative management of patient with $\mathrm{CABG}$ are not significant association between the pre- test knowledge scores and these selected demographic variables.

Conflicts of Interest: None declared.

Funding: There is no funding relevant to this study.

Ethical Clearance: Taken from Review Board of Ethical Research Committee, Mosul City for granting us the ethical approval for the study.
Acknowledgment: The authors wish to thank and acknowledge the members of the Review Board of Ethical Research Committee, Mosul City for granting us the ethical approval for the study. Finally, the study participants are highly appreciated for their valuable time and support.

\section{References}

1. Mathers CD, Loncar DJPm. Projections of global mortality and burden of disease from 2002 to 2030 . 2006;3(11):e442.

2. Elizondo-Omaña R, García-Rodríguez M, MoralesGómez J, Guzmán-López S, Tijerina de la Garza O, Fernandez-Rodarte B, et al. Conductos vasculares utilizados en la operación de revascularización miocárdica. 2005;7(29).

3. ElBardissi AW, Aranki SF, Sheng S, O’Brien SM, Greenberg CC, Gammie JSJTJot, et al. Trends in isolated coronary artery bypass grafting: an analysis of the Society of Thoracic Surgeons adult cardiac surgery database. 2012;143(2):273-81.

4. Fredericks S, Sidani S, Vahabi M, Micevski VJCJoNRA. An examination of current patient education interventions delivered to culturally diverse patients following CABG surgery. 2012;44(1).

5. Jha AK, Fisher ES, Li Z, Orav EJ, Epstein AMJNEJoM. Racial trends in the use of major procedures among the elderly. 2005;353(7):68391.

6. Hobbs RD, Paone G, D'Agostino RS, Jacobs JP, McDonald DE, Prager RL, et al. Myocardial revascularization: the evolution of the STS database and quality measurement for improvement. 2018;34(3):222-9.

7. Harskamp RE, Alexander JH, Ferguson Jr TB, Hager R, Mack MJ, Englum B, et al. Frequency and predictors of internal mammary artery graft failure and subsequent clinical outcomes: insights from the Project of Ex-vivo Vein Graft Engineering via Transfection (PREVENT) IV trial. 2016;133(2):131-8.

8. Møller CH, Perko MJ, Lund JT, Andersen LW, Kelbæk H, Madsen JK, et al. Three-year follow-up in a subset of high-risk patients randomly assigned to off-pump versus on-pump coronary artery bypass surgery: the Best Bypass Surgery trial. 2011;97(11):907-13. 
9. Mohr FW, Morice M-C, Kappetein AP, Feldman TE, Ståhle E, Colombo A, et al. Coronary artery bypass graft surgery versus percutaneous coronary intervention in patients with three-vessel disease and left main coronary disease: 5-year followup of the randomised, clinical SYNTAX trial. 2013;381(9867):629-38.

10. Puskas J, Cheng D, Knight J, Angelini G, DeCannier $\mathrm{D}$, Diegeler A, et al. Off-pump versus conventional coronary artery bypass grafting: a meta-analysis and consensus statement from the 2004 ISMICS consensus conference. 2005;1(1):3-27.

11. Diodato M, Chedrawy EGJSr, practice. Coronary artery bypass graft surgery: the past, present, and future of myocardial revascularisation. 2014;2014.

12. Partridge RA, Proano L, Marcozzi D, Garza AG, Nemeth I, Brinsfield K, et al. Oxford American handbook of disaster medicine: Oxford University Press; 2011.

13. Perrin KO, MacLeod CE. Understanding the essentials of critical care nursing: Pearson Higher Ed; 2012.

14. Bonaros N, Schachner T, Wiedemann D, Oehlinger A, Ruetzler E, Feuchtner G, et al. Quality of life improvement after robotically assisted coronary artery bypass grafting. 2009;114(1):59-66.

15. Weiss AJ, Elixhauser AJHC, Briefs UPS. Trends in operating room procedures in US hospitals, 20012011: statistical brief\# 171. 2006.

16. Ozcan H, Yildiz Findik U, Sut NJIjonp. Information level of patients in discharge training given by nurses following open heart surgery. 2010;16(3):289-94.

17. Eckman M, Comerford KJPLW, May WR. Medical-surgical nursing made incredibly easy. 2012;1:2016.

18. Carinci F, Van Gool K, Mainz J, Veillard J, Pichora $\mathrm{E}$, Januel J, et al. Towards actionable international comparisons of health system performance: expert revision of the OECD framework and quality indicators. 2015;27(2):137-46.

19. Head SJ, Milojevic M, Taggart DP, Puskas JDJC. Current practice of state-of-the-art surgical coronary revascularization. 2017;136(14):1331-45.

20. Theobald K, McMurray AJJoan. Coronary artery bypass graft surgery: discharge planning for successful recovery. 2004;47(5):483-91.
21. Sakr MD, Metwaly EA, Taha NMJENJ. Effect of intervention guidelines on nursing performance regarding patients with angina. 2019;16(2):70.

22. Ahmed AJUMTiMSN, Faculty of Nursing. Developing nursing care standards for patient with disectomy at Assuit University Hospital. 2013:74.

23. AhmedG, MohammedZ, Ghanem HJJAS. Coronary artery bypass grafting effect of developing and implementing nursing care standards on patient's outcomes. 2015;11(7):181-8.

24. Taha AJIJoN, Science H. Impact of a Designed Teaching Protocol about Nursing Management of Coronary Artery Bypass Grafting on Nurse's Knowledge, Practices and Patient's Outcome. 2017;6:13-28.

25. Hamed SJUMT, Faculty of Nursing, Benha University. Nurses performance during cardiopulmonary resuscitation in Intensive Care Unit and Cardiac Care Unit at benha University hospital. 2009.

26. Fuster V, Rydén LE, Asinger RW, Cannom DS, Crijns HJ, Frye RL, et al. ACC/AHA/ ESC guidelines for the management of patients with atrial fibrillation: executive summary: a report of the American College of Cardiology/ American Heart Association Task Force on Practice Guidelines and the European Society of Cardiology Committee for Practice Guidelines and Policy Conferences (Committee to Develop Guidelines for the Management of Patients With Atrial Fibrillation) Developed in collaboration with the North American Society of Pacing and Electrophysiology. 2001;38(4):1231-65.

27. Sosin M, Yin C, Poysophon P, Patel KMJJorm. Understanding the concepts and physiologic principles of lymphatic microsurgery. 2016;32(08):571-9.

28. Mark KA, Franks Jr AGJJotAAoD. Colchicine and indomethacin for the treatment of relapsing polychondritis. 2002;46(2):S22-S4.

29. THOMAS J. EFFECTIVENESS OF PLANNED TEACHING PROGRAMME ON KNOWLEDGE REGARDING POST OPERATIVE MANAGEMENT OF PATIENTS WITH CABG AMONG STAFF NURSES WORKING IN POST OPERATIVE CARDIAC UNITS OF SELECTED HOSPITALS AT MANGALORE 2013. 
1080 Medico-legal Update, January-March 2021, Vol. 21, No. 1

30. Soares JJ, Jablonska BJEJoP. Psychosocial experiences among primary care patients with and without musculoskeletal pain. 2004;8(1):79-89.

31. Koller A, Stein DJ. Pharmacotherapy of posttraumatic stress disorder. Anxiety Disorders. 29: Karger Publishers; 2013. p. 154-63.

32. Kumaraswamy M. Clinical Study of Epigastric swellings: RGUHS; 2006. 